\title{
PAPERS
}

\section{Complete and incomplete intestinal metaplasia at the oesophagogastric junction: prevalences and associations with endoscopic erosive oesophagitis and gastritis}

\author{
M Voutilainen, M Färkkilä, M Juhola, J-P Mecklin, P Sipponen, and The Central Finland \\ Endoscopy Study Group
}

atrophic gastritis (OR 2.1, 95\% CI 1.1 to 5.2), and multifocal atrophic gastritis (OR $7.1,95 \%$ CI 2.5 to 19.8 ). In univariate analysis, junctional complete IM was strongly associated with chronic cardia inflammation and cardia $H$ pylori infection $(\mathbf{p}<0.001)$.

Conclusions-Both complete and incomplete junctional IM are independent acquired lesions that increase in prevalence with age. Although IM subtypes often occur simultaneously, they show remarkable differences in their associations with gastritis and erosive oesophagitis: junctional complete $I M$ is a manifestation of multifocal atrophic gastritis, while the incomplete form (SCE) may result from carditis and gastro-oesophageal reflux disease. The frequency of dysplasia in intestinal metaplasia at the oesophagogastric junction appears to be low. (Gut 1999;45:644-648)

Keywords: intestinal metaplasia; oesophagogastric junction; oesophagitis; gastritis; gastro-oesophageal reflux disease; Helicobacter pylori

Intestinal metaplasia (IM) is commonly detected in random biopsy specimens taken immediately distal to the normally located squamocolumnar junction. ${ }^{1-6}$ IM at the oesophagogastric junction is a topic of great interest, because it may aetiopathogenetically be linked to the adenocarcinoma at this location. ${ }^{7}$ The incidence of this carcinoma has increased at a rate exceeding that of any other cancer. ${ }^{8}$ Whether IM at the oesophagogastric junction is a consequence of gastrooesophageal reflux disease or a manifestation of multifocal gastritis caused by Helicobacter pylori is unclear.

IM is histopathologically divided into three subgroups based on the mucin content of the columnar-type and goblet cells. ${ }^{9}{ }^{10}$ In the complete form of IM (type I), the columnar cells

Abbreviations used in this paper: IM, intestinal metaplasia; SCE, specialised columnar epithelium. 
are absorptive and contain neutral mucins, whereas in the incomplete forms of IM, they are at least partly secretory and contain acidic sialomucins (type II) or sulphomucins (type III). ${ }^{10} 11$ IM types II and III are commonly referred to as incomplete IM or specialised columnar epithelium (SCE) and are easily recognised with simple histochemical stains such as alcian blue ( $\mathrm{pH}$ 2.5)-periodic acid Schiff. ${ }^{12}$ SCE is the histological hallmark of Barrett's oesophagus. ${ }^{12}$

This study set out to examine the prevalences and demographics of complete IM and SCE at the oesophagogastric junction in a large consecutive series of dyspeptic patients sent for open access gastroscopy. We wanted to evaluate the associations between these IM subtypes and gastritis, $H$ pylori infection, and endoscopic and histological signs of gastro-oesophageal reflux disease, as well as the extent to which junctional complete IM and SCE are similar or dissimilar in these associations.

\section{Methods}

PATIENTS

The study population totalled 1698 consecutive dyspeptic patients sent for gastroscopy over a four month period. The patients with classical Barrett's oesophagus-that is, SCE detected above the oesophagogastric junction (n = 28) -were excluded. Patients for whom no adequate gastric antral, corpus, and oesophagogastric junctional biopsy specimens were available were also excluded, leaving a final study population of 1058 patients.

ENDOSCOPY

Two biopsy specimens were obtained from the gastric antrum $2 \mathrm{~cm}$ or more from the pylorus, and two others from the large curve of the gastric body, the oesophagogastric junction, and the distal oesophagus $2 \mathrm{~cm}$ or more above the junction (eight samples in all).

The oesophagogastric junctional biopsy specimens were obtained by first identifying the junction between the oesophagus and stomach at the level of the proximal end of the gastric folds. ${ }^{1314}$ The normal squamocolumnar mucosal junction, or $\mathrm{Z}$ line, is coincident with the aforementioned junction. ${ }^{14}$ In this report, junctional IM denotes the IM detected in biopsy specimens obtained immediately distal

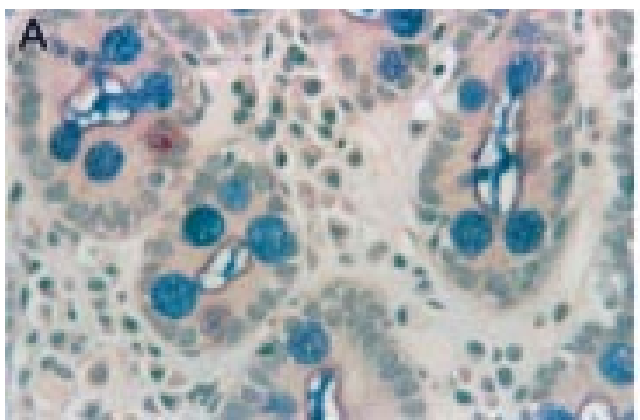

to normal appearing $\mathrm{Z}$ line. Junctional biopsy specimens were obtained under direct vision with the gastroscope in antegrade position. If gastric type mucosa extended circumferentially or as tongues above the oesophagogastric junction, biopsy specimens were taken separately from this mucosa to detect Barrett's oesophagus. Subjects with Barrett's oesophagus or incomplete IM detected in the oesophagus were excluded from the present analysis.

Subjects with endoscopic oesophagitis grades II-IV by Savary-Miller classification ${ }^{15}$ were classified as having erosive oesophagitis.

\section{HISTOLOGY}

Formalin fixed biopsy samples were embedded in paraffin wax, and tissue sections stained with haematoxylin-eosin, alcian blue ( $\mathrm{pH}$ 2.5)periodic acid Schiff, and modified Giemsa. The presence of gastritis, activity of gastritis, gastric gland atrophy, IM, and $H$ pylori infection were classified according to the Sydney System. ${ }^{16}$ Chronic gastritis subtypes were classified as follows: 1, normal gastric histology; 2, antral predominant gastritis (inflammation or inflammatory activity more severe in the gastric antrum than in the corpus, but no gastric gland atrophy); 3, antral predominant atrophic gastritis (gastric gland atrophy detected in the antrum but not the corpus); 4, corpus predominant gastritis (gastric gland atrophy detected only in the corpus or non-atrophic gastritis with more severe inflammation or inflammatory activity in the corpus); 5, multifocal atrophic gastritis (gastritis with atrophy detected in both the antrum and corpus).

The presence of complete and/or incomplete IM, chronic inflammation, and $H$ pylori infection in the cardia was evaluated in junctional biopsy specimens. Only cases showing typical mucus secreting glandular gastric cardia epithelium ${ }^{17}$ were included in this study. Chronic cardia inflammation was defined as infiltration of the lamina propria by lymphocytes and plasma cells. ${ }^{18}$ Complete IM was defined as the presence of goblet cells without acidic alcian blue ( $\mathrm{pH}$ 2.5)-periodic acid Schiff positive material in columnar-type cells. ${ }^{19}$ Incomplete IM or SCE was defined as the presence of goblet cells, with acidic mucins in goblet and adjacent columnar-appearing cells. ${ }^{19}{ }^{20}$ Figure 1 shows examples of complete

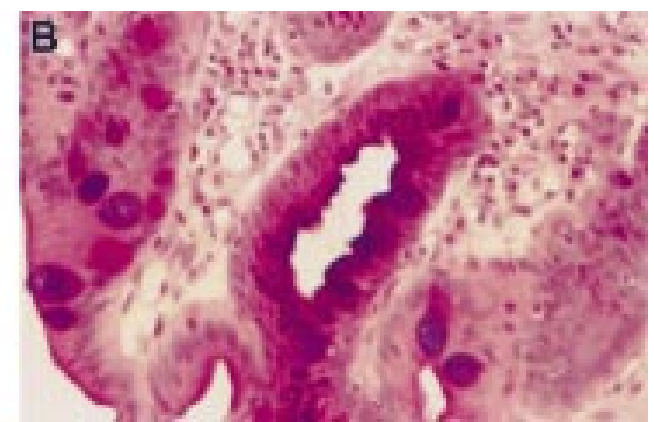

Figure 1 Complete intestinal metaplasia (IM) is characterised by goblet cells stained red or blue by alcian blue ( $p H$ 2.5)-periodic acid Schiff stain and by the presence of absorptive non-goblet cells $(A)$. Incomplete IM or specialised columnar epithelium is differentiated from the complete IM subtype by the presence of goblet cells intermixed with mucin-secreting columnar-appearing non-goblet cells staining red and blue by the alcian blue ( $p H 2.5$ )-periodic acid Schiff $\operatorname{stain}(B)$. 
and incomplete forms of metaplasia. Dysplasia, when present and definite, was graded as low grade or high grade. ${ }^{12}$ The study population was divided into three groups according to the histological findings at the oesophagogastric junction: group 1 , patients with only complete type junctional IM; group 2, patients with SCE

Table 1 Demographic, endoscopic, and histological characteristics of patients with junctional complete or incomplete intestinal metaplasia (IM) compared with those of the control group without these lesions

\begin{tabular}{llll}
\hline & $\begin{array}{l}\text { Functional complete } \\
I M(\%)(n=134)\end{array}$ & $\begin{array}{l}\text { functional incomplete } \\
I M(\%)(n=101)\end{array}$ & $\begin{array}{l}\text { Non-IM group } \\
(\%)(n=823)\end{array}$ \\
\hline Mean (95\% CI) age (y) & $65.0(62.5$ to 67.4$)$ & $65.3(62.8$ to 67.7$)$ & $54.9(53.8$ to 56.1$)$ \\
Male:female & $1: 1.5$ & $1: 1.2$ & $1: 1.5$ \\
Reflux symptoms & $17(11-24)$ & $14(7-21)$ & $14(13-17)$ \\
NSAID use & $21(14-28)$ & $28(19-37)$ & $22(19-25)$ \\
Smoking & $21(7-42)$ & $26(17-36)$ & $19(13-29)$ \\
Endoscopic erosive oesophagitis & $13(7-18)$ & $22(14-30)^{\star \star}$ & $13(11-15)$ \\
Hiatal hernia & $10(2-27)$ & $25(14-40)$ & $18(14-22)$ \\
Histological oesophagitis & $27(19-34)$ & $21(13-29)$ & $26(23-29)$ \\
Gastric H pylori infection & $55(47-64)^{\star \star}$ & $52(42-61)^{\star}$ & $39(36-42)$ \\
Carditis & $87(82-93)^{\star \star \star}$ & $92(85-97)^{\star \star \star}$ & $73(70-76)$ \\
Cardiac H pylori infection & $38(30-46)^{\star \star \star}$ & $32(23-41)$ & $24(21-27)$ \\
\hline
\end{tabular}

Smoking and hiatal hernia were analysed only for a subgroup. Helicobacter pylori was diagnosed histologically. "Carditis" is chronic inflammation in histologically verified gastric cardiac mucosa. ${ }^{\star} \mathrm{p}<0.05,{ }^{\star \star} \mathrm{p}<0.01,{ }^{\star \star \star} \mathrm{p}<0.001$ compared with non-IM group.

CI, confidence interval; NSAID, non-steroidal anti-inflammatory drug.

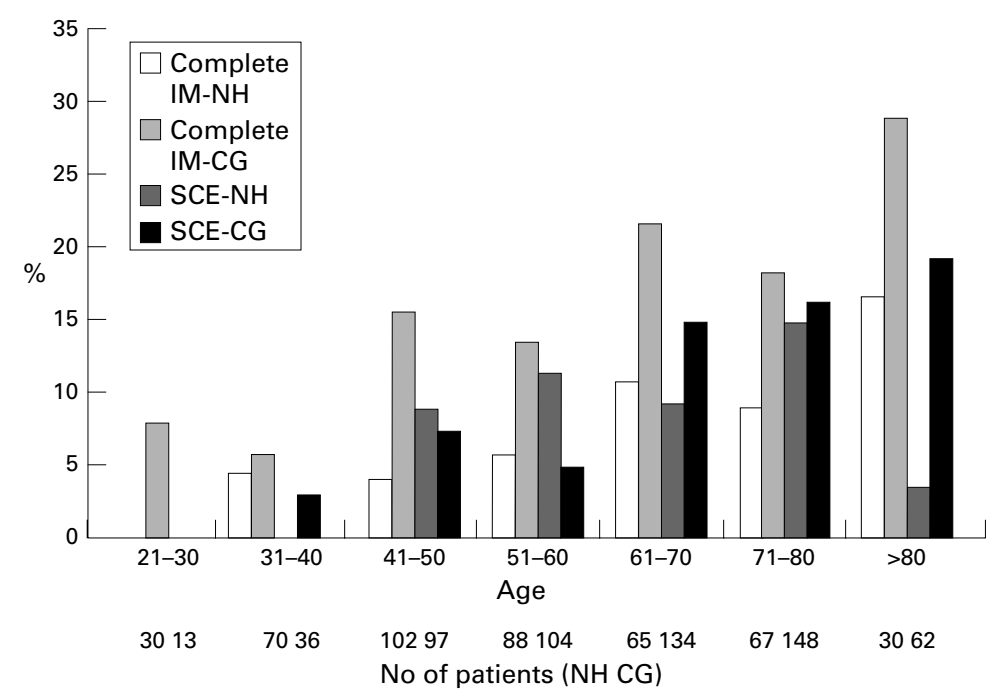

Figure 2 Prevalences of junctional complete and incomplete (specialised columnar epithelium, SCE) intestinal metaplasia (IM) in different age groups. NH, normal gastric histology $(n=426)$; CG, chronic gastritis $(n=632)$. The correlation of age with both IM types was significant in the $C G(p<0.001$ for complete IM and incomplete IM) and NH $(p=0.001$ for complete IM and $p=0.002$ for incomplete IM) group.

Table 2 The prevalences of oesophagogastric junctional complete and incomplete intestinal metaplasia (IM) in different types of gastritis

\begin{tabular}{lll}
\hline & $\begin{array}{l}\text { functional complete IM } \\
(n=134)\end{array}$ & $\begin{array}{l}\text { functional incomplete IM } \\
(n=101)\end{array}$ \\
\hline $\begin{array}{l}\text { Normal gastric histology }(\mathrm{n}=417) \dagger \\
\text { Antral predominant non-atrophic gastritis } \\
(\mathrm{n}=421,78 \% \text { pylori } \text { positive } \ddagger)\end{array}$ & $24(18 ; 11$ to 24$)$ & $29(29 ; 20 \text { to } 38)^{\star}$ \\
$\begin{array}{c}\text { Antral predominant atrophic gastritis } \\
(\mathrm{n}=86,81 \% \text { pylori positive) }\end{array}$ & $60(45 ; 36$ to 53$)$ & $40(40 ; 30$ to 49$)$ \\
$\begin{array}{c}\text { Corpus predominant atrophic gastritis } \\
(\mathrm{n}=75,26 \% \text { pylori } \text { positive) }\end{array}$ & $18(13 ; 8$ to 19$)$ & $20(20 ; 12$ to 28$)$ \\
$\begin{array}{c}\text { Multifocal atrophic gastritis } \\
(\mathrm{n}=360,57 \% \text { H pylori } \text { positive) }\end{array}$ & $15(11 ; 6 \text { to } 17)^{\star \star}$ & $2(2 ; 0$ to 7$)$ \\
$\begin{array}{c}\text { Chronic gastritis, all types } \\
(\mathrm{n}=618,71 \% \text { H pylori } \text { positive) }\end{array}$ & $110(82 ; 76 \text { to } 89)^{\star}$ & $72(71 ; 63$ to 80$)$ \\
\hline
\end{tabular}

Values in parentheses are percentage with 95 confidence interval of the total amount of the IM subtype.

Within each type of gastritis, the prevalences of IM subtypes were compared with each other using the rest of study population with junctional IM as reference group ( $\chi^{2}$ test).

†Total number of patients

$\ddagger$ Prevalence rates from histological examination

${ }^{\star} \mathrm{p}=0.05,{ }^{\star \star} \mathrm{p}=0.007$. or incomplete junctional IM ( $61 \%$ of them also had complete IM); group 3, control subjects without either type of IM.

Microscopic oesophagitis was defined as papillae extending into the upper third of the oesophageal mucosa with or without the infiltration of inflammatory cells. ${ }^{8}$

STATISTICAL ANALYSIS

$\chi^{2}$ and Mann-Whitney $U$ tests were used to compare groups, and $\mathrm{p}<0.05$ was considered as significant. Multiple logistic regression analysis was used to assess the relations between complete or incomplete IM and factors with a significant difference in prevalence in univariate analysis when the two groups were compared with the control group without these lesions. Odds ratios (OR) with their 95\% confidence intervals $(95 \% \mathrm{CI})$ are reported for independent risk factors for the complete and incomplete IM forms.

ETHICS

This study was approved by the ethics committee of Jyväskylä Central Hospital.

\section{Results}

The study population consisted of 1058 patients (mean age 57.3 years, $95 \%$ CI 56.3 to 58.3 and male to female ratio 1:1.5), of whom $134(13 \%)$ had complete IM and $39(4 \%)$ incomplete IM (SCE) as the sole type of IM at the oesophagogastric junction. The mean age of the "pure" complete IM group was 65.0 (95\% CI 62.5 to 67.4 ) years and that of the "pure" incomplete IM group 62.9 (95\% CI 58.5 to 67.3 ) years. A total of 62 patients harboured both types of IM simultaneously, giving overall prevalence for complete IM of $19 \%$ ( $\mathrm{n}=$ 196), and for incomplete IM or SCE of $10 \%$ (n =101). Henceforth patients with complete IM denotes the patients with this type of IM only ( $n=134)$, whereas the incomplete IM or SCE group refers to patients with SCE only plus those with complete IM as well as SCE ( $\mathrm{n}=$ 101).

The patients with complete or incomplete IM were older than those without either lesion (table 1, both patients with chronic gastritis and normal stomach included). In subjects with normal stomach, the mean age of the non-IM-non-SCE group was 50.8 (95\% CI 48.4 to 53.2 ) years, that of the junctional complete IM group 62.4 (95\% CI 56.3 to 68.5 ) years, $(p=0.001)$, and that of the junctional SCE group 54.0 (95\% CI 46.3 to 61.7) years $(\mathrm{p}=0.003)$. The difference in mean age between the complete IM and SCE group was insignificant $(p=0.1)$. Both types of junctional IM correlated with age in patients with normal gastric histology or with chronic gastritis (fig 2). The sex ratios of patients with either type of junctional IM were not significantly different from that of the control group. In patients with multifocal atrophic gastritis, complete junctional IM was significantly more common than incomplete junctional IM (table 2). On the other hand, in patients with histologically normal stomach, junctional incomplete IM was more common than complete IM, although the 
Table 3 Results of multivariate analyses to determine the independent risk factors for junctional complete and incomplete intestinal metaplasia

\begin{tabular}{ll}
\hline & $\begin{array}{l}\text { Odds ratio (95\% } \\
\text { confidence interval) }\end{array}$ \\
\hline $\begin{array}{l}\text { Complete junctional intestinal metaplasia } \\
\text { Age }\end{array}$ & $1.2(1.0$ to 1.4$)$ \\
"Carditis" & $1.2(0.6$ to 2.2$)$ \\
Cardia H pylori & $1.8(0.9$ to 3.8$)$ \\
Gastric H pylori & $0.7(0.3$ to 1.4$)$ \\
Antral predominant non-atrophic gastritis & $2.6(1.3$ to 5.2$)$ \\
Antral predominant atrophic gastritis & $2.1(1.1$ to 5.2$)$ \\
Corpus predominant (atrophic) gastritis & $1.0(0.5$ to 2.2$)$ \\
Multifocal atrophic gastritis & $7.1(2.5$ to 19.8$)$ \\
Incomplete junctional intestinal metaplasia & \\
Age & $1.3(1.2$ to 1.6$)$ \\
Endoscopic erosive oesophagitis & $1.9(1.1$ to 3.2$)$ \\
"Carditis" & $2.9(1.3$ to 6.2$)$ \\
Antral predominant non-atrophic gastritis & $1.4(0.9$ to 2.4$)$ \\
Gastric H pylori & $1.0(0.6$ to 1.7$)$ \\
\hline
\end{tabular}

Age is given per decade.

difference did not reach statistical significance (table 2). Junctional epithelial dysplasia was not observed in any patient with complete or incomplete junctional IM.

Reflux symptoms, smoking habits, or the use of non-steroidal anti-inflammatory drugs did not correlate with the presence of either type of IM (table 1). Hiatal hernia or histological oesophagitis did not predict the presence of junctional IM of either type.

Multivariate analysis showed that age, antral predominant non-atrophic gastritis, antral predominant atrophic, and multifocal atrophic gastritis were independent risk factors for "pure" complete junctional IM (table 3). Independent risk factors for junctional SCE were age, endoscopic erosive oesophagitis, and chronic cardia inflammation ("carditis") (table 3).

\section{Discussion}

This study showed complete and incomplete IM to be common findings at the oesophagogastric junction in a consecutive series of dyspeptic patients: almost a quarter of our study population had either or both forms of the lesion. Previously reported prevalence rates varied from 5.3 to $36 \% .^{2-462122}$ The width of this range may be due to patient selection or to different methods of biopsy sampling or staining for histology. Haematoxylin-eosin stain yields lower IM rates than the simultaneous application of alcian blue $(\mathrm{pH}$ 2.5)-periodic acid Schiff, which also enables differentiation between complete and incomplete IM. ${ }^{6} 192023$

The prevalence of junctional complete IM and SCE at the oesophagogastric junction increased with age, and both IM subtypes were also found in patients without concomitant gastritis, indicating that junctional IM and SCE are acquired local lesions. Complete IM and SCE seemed to occur in men and women at similar frequencies, contrasting with Barrett's oesophagus and oesophagogastric junctional adenocarcinomas which are strongly male predominant diseases. ${ }^{12} 2425$

An important finding was that, in multivariate analysis, endoscopic erosive oesophagitis, but not $H$ pylori infection or antral predominant gastritis, was an independent risk factor for junctional SCE. In contrast, complete junc- tional IM was associated with gastritis, and particularly with multifocal atrophic gastritis, but not with endoscopic erosive oesophagitis. These observations suggest that at least some subjects with junctional SCE suffer this lesion as a consequence of gastro-oesophageal reflux disease, while complete junctional IM is a manifestation of multifocal atrophic gastritis and $H$ pylori infection. However, in patients with normal stomach, complete junctional IM may result from gastro-oesophageal reflux disease, because this IM subtype was detected in $6 \%$ of this subgroup.

In the stomach, IM represents a sequence of progressive lesions from complete (type I or "small bowel type IM") to incomplete (types II and III or "colonic type IM") IM. ${ }^{26}{ }^{27}$ This may also be the case with IM at the oesophagogastric junction. However, this hypothesis was not supported by the finding that junctional complete IM and SCE were detected at a similar age in subjects with normal gastric histology. Proper and correct analysis of the background factors for junctional IM subtypes is difficult because obviously there are varying degrees of overlap with regard to the pathogenic factors for junctional complete IM and SCE.

The present findings suggest important clinical and practical conclusions on junctional SCE: the presence of SCE at the oesophagogastric junction in subjects with a normal stomach - that is, histologically normal antral and gastric corpus mucosa-may predict gastro-oesophageal reflux disease with high certainty. This could also apply to junctional SCE patients with chronic gastritis. The presence of complete junctional IM may not indicate reflux, but is a manifestation of multifocal atrophic gastritis. These conclusions are concordant with an earlier study indicating that junctional SCE is related to gastro-oesophageal reflux disease detected by 24 hour oesophageal $\mathrm{pH}$ monitoring. ${ }^{28}$

In this study, none of the patients with junctional IM showed dysplasia, which accords with an earlier report. ${ }^{5}$ Dysplasia is quite a common finding at Barrett's epithelium and precedes the appearance of adenocarcinoma. ${ }^{12}$ This may also be the case in the adenocarcinomas of the oesophagogastric junction, which are on the increase in many western countries. ${ }^{242529}$ The low rate of dysplasias in junctional IM suggests that neither junctional SCE nor complete IM are as high risk carcinoma precursor lesions as Barrett's oesophagus is for oesophageal adenocarcinoma. On the other hand, junctional complete IM and SCE are common lesions, and the absence of dysplasia in a limited number of patients does not exclude the possibility that junctional SCE or complete IM could progress to dysplasia and carcinoma in some patients.

In conclusion, this study indicates that complete and incomplete IM at the oesophagogastric junction are common acquired lesions. They may not be directly related to Barrett's oesophagus or junctional adenocarcinomas because of the differences in their basic demographics. It seems that incomplete junctional IM (SCE) and complete IM are dissimilar 
lesions in terms of their pathogenesis: the former seems to be a consequence of gastrooesophageal reflux disease and the latter a manifestation of multifocal atrophic gastritis.

In addition to the authors, the following doctors are members of The Central Finland Endoscopy Study Group: Liisa AhlskogMuraja, Teuvo Antikainen, Sirpa Antila, Jorma Anttinen, Matti
Hallikas, Kari-Pekka Hämäläinen, Heikki Janhonen, Matti Kairaluoma, Kerkko Karjalainen, Pekka Kauranen, Matti Kolu, Heikki Korhonen, Jari Korhonen, Ritva Koskela, Raimo Krees, Ilkka Kunnamo, Vesa Käriä, Päivi Laaksonen, Matti Laukkanen, Reino Liisanantti, Marja Lohman, Timo Mäntynen, Kyösti Nuorva, Antero Palmu, Ulla Palmu, Matti Pellinen, Pertti Särkkä, Harri Selänne, Tuula Tervo, Marianne Udd, Jukka Viinikka.

1 Genta RM, Huberman RM, Graham DY. The gastric cardia in Helicobacter pylori infection. Hum Pathol 1994;25:91519.

2 Spechler SJ, Zeroogian JM, Antonioli DA, et al. Prevalence of metaplasia at the gastro-oesophageal junction. Lancet 1994;344:1533-6.

3 Johnston MH, Hammond AS, Laskin WL, et al. The prevalence and clinical characteristics of short segments of specialized intestinal metaplasia in the distal esophagus on routine endoscopy. Am f Gastroenterol 1996;91:1507-11.

4 Weston AP, Krmpotich P, Makdisi WF, et al. Short segment Barrett's esophagus: clinical and histological features, assoBarrett's esophagus: clinical and histological features, asso-
ciated endoscopic findings, and association with gastric ciated endoscopic findings, and association with gastric
intestinal metaplasia. Am $\mathcal{F}$ Gastroenterol 1996;91:981-6.

5 Morales TG, Sampliner RE, Bhattacharyya A. Intestinal metaplasia of the gastric cardia. Am $\mathcal{F}$ Gastroenterol 1997;92:414-18.

6 Nandurkar S, Talley NJ, Martin CJ, et al. Short segment Barrett's oesophagus: prevalence, diagnosis and associations. Gut 1997;40:710-15.

7 Cameron AJ, Lomboy CT, Pera M, et al. Adenocarcinoma of the esophagogastric junction and Barrett's esophagus. Gastroenterology 1995;109:1541-6.

8 Fuchs CS, Mayer RJ. Gastric carcinoma. N Engl f Med 1995;333:32-9.

9 Jass JR. Role of intestinal metaplasia in the histogenesis of gastric carcinoma. $\mathcal{F}$ Clin Pathol 1980;33:801-10.

10 Filipe MI, Potet F, Bogomoletz WV, et al. Incomplete sulphomucin-secreting intestinal metaplasia for gastric sulphomucin-secreting intestinal metaplasia for gastric cancer. Preliminary data from a prost

11 Shah KA, Deacon AJ, Dunscombe P, et al. Intestinal metaplasia subtyping: evaluation of Gomori's aldehyde fuchsin for routine diagnostic use. Histopathology 1997;31:277-83.

12 Haggitt RC. Barrett's esophagus, dysplasia, and adenocarcinoma. Hum Pathol 1994;25:982-93.
13 McClave SA, Boyce Jr HW, Gottfried MR. Early diagnosis of columnar-lined esophagus: a new endoscopic criterion. Gastrointest Endosc 1987;33:413-16.

14 Tytgat GNJ, Hameeteman W, Onstenk R, et al. The spectrum of columnar-lined esophagus: Barrett's esophagus. Endoscopy 1989;21:177-85.

15 Savary M, Miller G, eds. The esophagus. Handbook and atlas of endoscopy. Solothurn, Switzerland: Gassman Verlag AG, 1978:135-9.

16 Price AB. The Sydney system: histological division. $f$ Gastroenterol Hepatol 1991;6:209-22.

17 Owen DA. Normal histology of the stomach. Am $\mathcal{F}$ Surg Pathol 1986;10:48-61.

18 Riddell RH. The biopsy diagnosis of gastroesophageal reflux disease, "carditis," and Barrett's esophagus, and sequelae of therapy. Am 7 Surg Pathol 1996;20(suppl):S31-51.

19 Jauregui HO, Davessar K, Hale JH, et al. Mucin histochemistry of intestinal metaplasia in Barrett's esophagus. Mod Pathol 1988;1:188-92.

20 Gottfried MR, McClave SA, Boyce HW. Incomplete intestinal metaplasia in the diagnosis of columnar lined esophagus (Barrett's esophagus). Am f Clin Pathol 1989;92: 741-6.

21 Hirota WK, Loughney TM, Lazas DJ, et al. The prevalence and demographics of specialized intestinal metaplasia at the esophagogastric junction in a cohort of 889 prospectively studied patients [abstract]. Gastroenterology 1997; 112:A149

22 Trudgill NJ, Suvarna SK, Kapur KC, et al. Intestinal metaplasia at the squamocolumnar junction in patients attending for diagnostic gastroscopy. Gut 1997;41:585-9.

23 Weinstein WM, Ippoliti AF. The diagnosis of Barrett's esophagus: goblets, goglets, goblets. Gastrointest Endosc 1996;44:91-5.

24 Blot WJ, DeVesa SS, Kneller RW, et al. Rising incidence of adenocarcinoma of the esophagus and gastric cardia. ҒAMA 1991;265:1287-9.

25 Pera M, Cameron AJ, Trastek VF, et al. Increasing incidence of adenocarcinoma of the esophagus and esophagogastric junction. Gastroenterology 1993;104:510-13.

26 Correa P. A human model of gastric carcinogenesis. Cancer Res 1988;48:3554-60.

27 Sipponen P, Seppälä K, Varis K, et al. Intestinal metaplasia with colonic type sulphomucins in the gastric mucosa. Acta Pathologica Microbiologica Scandinavica Section A 1976;23: 276-9.

28 Öberg S, Peters JH, DeMeester TR, et al. Inflammation and specialized intestinal metaplasia of cardiac mucosa is a manifestation of gastroesophageal reflux disease. Ann Surg 1997;226:522-32

29 Hansson L-E, Sparén P, Nyrén O. Increasing incidence of carcinoma of the gastric cardia in Sweden from 1970 to 1985. Br F Surg 1993;80:374-7. 